\title{
Epithelial recurrent erosion dystrophy
}

INSERM

\section{Source}

INSERM. (1999). Orphanet: an online rare disease and orphan drug data base. Epithelial recurrent erosion dystrophy. ORPHA:293381

Epithelial recurrent erosion dystrophy (ERED) is a rare form of superficial corneal dystrophy (see this term) characterized by recurrent episodes of epithelial erosions from childhood in the absence of associated diseases, with occasional impairment of vision. 